\title{
Evaluation of Three-Dimensional Porous Iron-Cross-Linked Alginate as a Scaffold for Cell Culture
}

\author{
Ikuko Machida-Sano, Sakito Ogawa, Makoto Hirakawa, and Hideo Namiki \\ Department of Biology, School of Education, Waseda University, 2-2 Wakamatsu-cho, Shinjuku-ku, Tokyo 162-8480, Japan \\ Correspondence should be addressed to Ikuko Machida-Sano; ikuko@ruri.waseda.jp
}

Received 26 November 2013; Accepted 31 December 2013; Published 6 February 2014

Academic Editors: P. Laurienzo and W.-B. Tsai

Copyright ( 2014 Ikuko Machida-Sano et al. This is an open access article distributed under the Creative Commons Attribution License, which permits unrestricted use, distribution, and reproduction in any medium, provided the original work is properly cited.

\begin{abstract}
We investigated the efficacy of three-dimensional porous ferric-ion-cross-linked alginate (Fe-alginate) gels as cell scaffolds, in comparison with calcium-ion-cross-linked alginate (Ca-alginate) gels. In a previous study, we had demonstrated that twodimensional $\mathrm{Fe}$-alginate film was an efficient material for use as a scaffold, allowing good cell adhesion and proliferation, unlike Caalginate film. In the present study, we fabricated three-dimensional porous $\mathrm{Fe}$ - and $\mathrm{Ca}$-alginate gels by freeze-drying and evaluated their effects on cultured cells. The Fe-alginate gels showed higher protein adsorption ability than Ca-alginate gels. Cells formed multicellular spheroids in both types of alginate scaffold, but the number of cultured cells increased with culture time on Fealginate porous gels, whereas those on Ca-alginate gels did not. Moreover, it was revealed that the cells on Fe-alginate scaffolds were still viable inside the multicellular spheroids even after cultivation for 14 days. These results suggest that Fe-alginate provides a superior porous scaffold suitable for three-dimensional culture of cells. Our findings may be useful for extending the application of Fe-alginate to diverse biomedical fields.
\end{abstract}

\section{Introduction}

For both research and therapeutic applications, fabrication of effective cell culture substrates is desirable. A suitable three-dimensional environment for cells is considered to be an important factor for in vitro cell cultivation, since cells within living organisms exist under such conditions. Two-dimensional cell culture is frequently used because it is convenient and manageable for the maintenance of cells and also for biological research. However, it has been reported that various cells lose their functions when cultured as a monolayer under two-dimensional conditions [1-5]. Thus, two-dimensional culture is considered to be an unnatural condition for many cell types. In order to overcome the shortcomings of two-dimensional culture, three-dimensional culture systems, such as multicellular spheroids, cellular multilayers, and matrix-embedded culture, have been devised [6]. Therefore, studies focusing on the optimal three-dimensional culture environment for cells have important implications.
In a previous study, we produced two-dimensional ferricion-cross-linked alginate (Fe-alginate) films and demonstrated that they supported good cell adhesion and proliferation [7]. Alginates are composed of 1,4-linked $\beta$-Dmannuronic acid (M) and $\alpha$-L-guluronic acid (G) residues, forming gels with certain multivalent metal ions $[8,9]$. By exploiting these characteristics, alginates can be shaped into various configurations and applied in a range of biomedical fields. Calcium-ion-cross-linked alginate (Ca-alginate) is the most frequently used ionically cross-linked alginate. However, it exhibits poor protein adsorptive capacity and thus has a low affinity for cells $[10,11]$. In contrast, we have found that $\mathrm{Fe}$-alginate films have superior protein adsorption ability and act as an effective cell culture substrate [7]. However, the cell culture properties of $\mathrm{Fe}$-alginate with a three-dimensional morphology have not been investigated.

The aim of this study was to clarify the effectiveness of $\mathrm{Fe}$-alginate gels to provide a three-dimensional culture environment for cell growth. We prepared three-dimensional 
porous $\mathrm{Fe}$ - and Ca-alginate gels using a freeze-drying technique. From observations of the behavior of seeded cells, we evaluated the efficiency of porous Fe-alginate gels as a cell scaffold using 3T3-L1 cells as a model. Here we describe the favorable cell proliferation that was observed on the three-dimensional $\mathrm{Fe}$-alginate gels, in contrast to that on $\mathrm{Ca}$ alginate gels, and the suitability of Fe-alginates, not only as two-dimensional films but also three-dimensional gels, as scaffolds for cell culture.

\section{Materials and Methods}

2.1. Materials. A high G-content alginate (I-1G) was purchased from KIMICA Corporation (Tokyo, Japan). Eagle's minimum essential medium (E-MEM) and Hanks' solution were obtained from Nissui Pharmaceutical (Tokyo, Japan), fetal bovine serum (FBS) was obtained from Invitrogen (Carlsbad, CA, USA), and trypsin was obtained from Becton Dickinson (Sparks, MD, USA). All other chemicals were purchased from Wako Pure Chemical Co. (Tokyo, Japan).

2.2. Preparation of Three-Dimensional Porous Alginate Scaffolds. Three-dimensional porous alginate gels were fabricated by freeze-drying. One milliliter of $2 \%(\mathrm{w} / \mathrm{v})$ alginate solution was poured into the wells of 24-well tissue culture plates, and $1 \mathrm{~mL}$ of $20 \mathrm{mM} \mathrm{FeCl}_{3}$ or $\mathrm{CaCl}_{2}$ was added to each well to induce cross-linkage of the alginate while stirring vigorously using a homogenizer at $25^{\circ} \mathrm{C}$. The final concentrations of polymer and cross-linking agents in cross-linked solutions were $1 \%$ and $10 \mathrm{mM}$, respectively. The resulting gels were frozen at $-20^{\circ} \mathrm{C}$ for $24 \mathrm{~h}$ and then at $-80^{\circ} \mathrm{C}$ for $24 \mathrm{~h}$. The frozen gels were lyophilized and sterilized by exposure to ultraviolet (UV) light for $1 \mathrm{~h}$. Before seeding of cells on the gels, the gels were stabilized by immersion in E-MEM at $37^{\circ} \mathrm{C}$ under a $5 \% \mathrm{CO}_{2}$ atmosphere for $72 \mathrm{~h}$, and the medium was replaced every $24 \mathrm{~h}$. The structures of the scaffolds were observed using a scanning electron microscope (SEM) (VE9800, KEYENCE, Osaka, Japan), after being sputter-coated with gold.

2.3. Analysis of Protein Adsorption Ability of Alginate Gels. Alginate gels, prepared as described above, were immersed in $0.2 \%$ FBS in PBS or PBS $(2 \mathrm{~mL} /$ well $)$ in a 24 -well tissue culture plate at $37^{\circ} \mathrm{C}$ for $2 \mathrm{~h}$. After incubation, the protein concentrations of the solutions were determined using a bicinchoninic acid (BCA) protein assay reagent kit (Thermo Fisher Scientific Pierce Biotechnology, IL, USA) in accordance with the manufacturer's instructions. Alginate gels, immersed in PBS, were used as controls. The amount of adsorbed protein was calculated from the differences in the protein concentrations of $0.2 \%$ FBS before and after immersion of the alginate gels. The eventual results were expressed as the adsorbed weight per $1 \mathrm{mg}$ of alginate scaffold, which was calculated from the gel dry weight.

2.4. Cell Culture. 3T3-L1 cells were cultured in E-MEM with $10 \%(\mathrm{v} / \mathrm{v}) \mathrm{FBS}$ at $37^{\circ} \mathrm{C}$ under a $5 \% \mathrm{CO}_{2}$ atmosphere. To detach the cells by trypsinization, they were incubated with
$0.25 \%(\mathrm{w} / \mathrm{v})$ trypsin and $0.02 \%(\mathrm{w} / \mathrm{v})$ EDTA in $\mathrm{Ca}^{2+}-, \mathrm{Mg}^{2+}-$ free phosphate-buffered saline (PBS) at $37^{\circ} \mathrm{C}$ for $10 \mathrm{~min}$. EMEM containing $10 \%(\mathrm{v} / \mathrm{v})$ FBS was subsequently added to terminate the enzyme reaction. The cell suspension was centrifuged at $1000 \times \mathrm{g}$ for $5 \mathrm{~min}$ and resuspended in E-MEM containing $10 \%(\mathrm{v} / \mathrm{v})$ FBS. The cells were counted with a Coulter Counter (Beckman Coulter Corporation, FL, USA) and seeded onto alginate gels in 24-well tissue culture plates at a density of $10 \times 10^{4}$ cells/well in $20 \mu \mathrm{L}$ of culture medium. Samples were incubated at $37^{\circ} \mathrm{C}$ under a $5 \% \mathrm{CO}_{2}$ atmosphere, and $1 \mathrm{~mL}$ of culture medium was added to each well at $2 \mathrm{~h}$ after cell seeding. The medium was replaced every day. After 1,7 , and 14 days, cell counting was performed to quantify the degree of cell proliferation. To count the attached cells, each film was transferred to another plate and washed with PBS. Then $1 \mathrm{~mL}$ of $200 \mathrm{mM}$ sodium citrate in Hanks' solution was added to dissolve the gels at $37^{\circ} \mathrm{C}$ for $2 \mathrm{~h}$. After incubations, the cells were disassembled by trypsinization at $37^{\circ} \mathrm{C}$ for $10 \mathrm{~min}$. The number of cells in the suspensions was counted with a Coulter Counter.

2.5. Observation of Cell Morphology on Alginate Gels. The morphology of the cells cultured on the alginate scaffolds was observed using SEM. The cells cultured on the scaffolds were washed twice in PBS and then fixed in $2.5 \%$ glutaraldehyde in PBS for $2 \mathrm{~h}$ at $4^{\circ} \mathrm{C}$. After being washed in PBS, the cells were dehydrated with 50\%, 70\%, 90\%, and 99.5\% ethanol for $20 \mathrm{~min}$ at each concentration. After being dehydrated, the alginate scaffolds were placed in tert-butyl alcohol and freeze-dried. The alginate scaffolds were then gold-coated and examined by SEM.

2.6. Measurement of Cell Viability on Fe-Alginate Gels. Cell viability was assessed using a dye solution capable of staining live cells. After 14 days of cultivation, cells in the Fe-alginate scaffolds were washed in E-MEM, and $5 \mu \mathrm{L}$ of Vybrant Dio Cell-Labeling Solution (Life Technologies Corporation, CA, USA) was added with $1 \mathrm{~mL}$ of E-MEM to stain the live cells. After incubation for $30 \mathrm{~min}$ at $37^{\circ} \mathrm{C}$ under a $5 \%$ $\mathrm{CO}_{2}$ atmosphere, the cells with the Fe-alginate scaffold were washed three times in E-MEM. The stained cells on the scaffold were observed using a confocal microscope (FV1000, Olympus, Tokyo, Japan).

2.7. Statistics. Statistical analysis was performed using KaleidaGraph version 4.0 software. The data were subjected to analysis of variance (ANOVA). Scheffe's test was used for post hoc evaluation of differences between the respective groups. For all statistical evaluations, significance was assigned at $P<$ 0.05 .

\section{Results}

3.1. Properties of the Porous Alginate Gels. The morphology of scaffolds, fabricated by freeze-drying, was observed by SEM (Figure 1). Both scaffolds, Fe- and Ca-alginate, exhibited a similar highly porous structure with interconnecting pores. The protein adsorption ability of the $\mathrm{Fe}$ - and Ca-alginate 


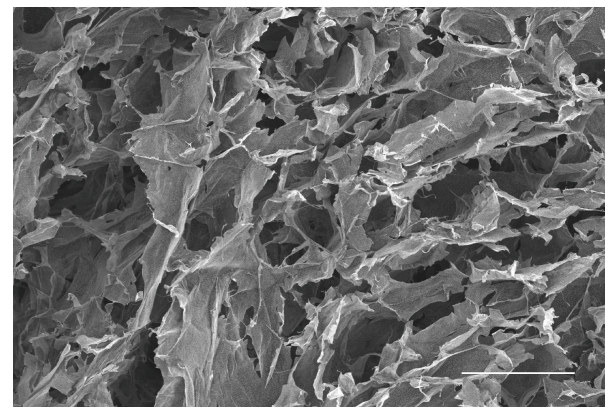

(a)

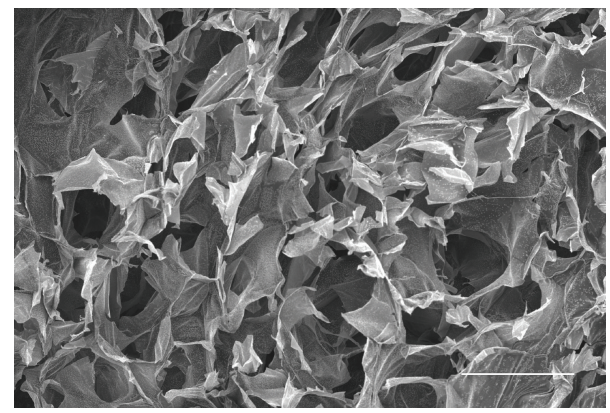

(b)

FIGURE 1: SEM micrographs of Fe- (a) and Ca- (b) alginate scaffolds. Bar equals $500 \mu \mathrm{m}$.

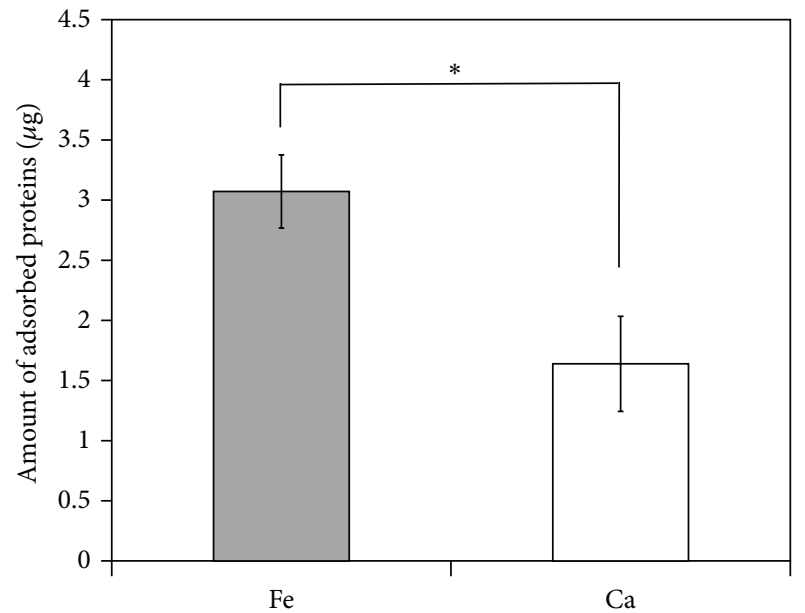

Figure 2: Protein adsorption on $\mathrm{Fe}$ - and Ca-alginate gels. The amount of total adsorbed serum proteins was quantified using a BCA protein assay kit. The amount of adsorbed protein was indicated as the weight of adsorbed protein per $1 \mathrm{mg}$ of alginate gel. Error bars indicate standard deviation for $n=6 .{ }^{*} P<0.05$.

porous gels was then investigated. The amounts of adsorbed serum proteins were about 2-fold higher on Fe-alginate gel surfaces than on Ca-alginate gels (Figure 2).

3.2. Cell Growth on the Porous Alginate Scaffolds. The suitability of three-dimensional porous alginate gels as cell scaffolds was evaluated by cultivation of 3T3-L1 cells on the respective gels. To investigate cell proliferation on the Fe-

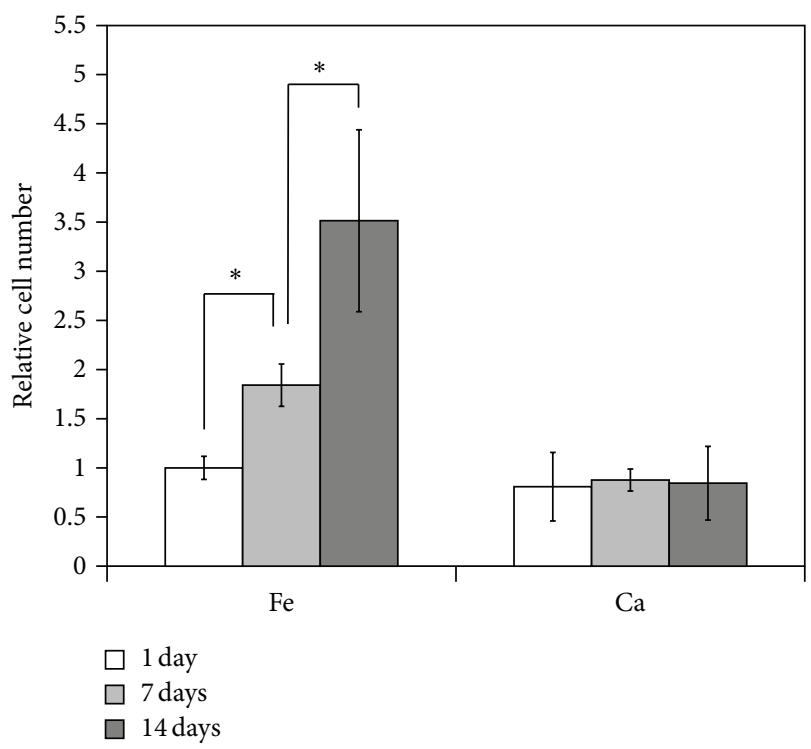

FIGURE 3: Proliferation of cells on alginate scaffolds. Cells were seeded onto $\mathrm{Fe}$ - and $\mathrm{Ca}$-alginate gels, and the numbers of attached cells were counted at 1,7 , and 14 days after the start of culture. The relative cell number was calculated from comparison with the number of cells at 1 day of cultivation on Fe-alginate gels. Error bars indicate standard deviation for $n=3 .{ }^{*} P<0.05$.

and Ca-alginate scaffolds, the number of cells on the gels was counted after incubation for 1, 7, and 14 days. The number of cells attached to the Fe-alginate gels increased as the culture period progressed, whereas almost no cell growth was evident on the Ca-alginate gels. From days 1 to 14, the number of attached cells on the Fe-alginate gels increased about 3.5-fold (Figure 3).

3.3. Cell Morphology and Viability on the Porous Alginate Scaffolds. The morphology of cells cultured on the alginate scaffolds was observed by SEM (Figure 4). Cell morphology analysis demonstrated that the cells formed multicellular spheroids on both types of alginate scaffold. It was also observed that the size of the spheroids on $\mathrm{Fe}$-alginate gels increased as the culture period progressed, suggesting good cell proliferation. Observation of living cells indicated that multicellular spheroids were widely distributed on the scaffolds (Figure 5(a)) and that cells present inside the spheroids were viable even after cultivation for 14 days (Figure 5(b)).

\section{Discussion}

The present study revealed that three-dimensional porous Fe-alginate was a suitable material for supporting good cell growth. In a previous study, we had demonstrated that two-dimensional Fe-alginate films were a superior culture substrate for cells. Ca-alginate is the most frequently used material among various ionically cross-linked alginates but is unsuitable for use as a cell scaffold. Therefore, it is considered that clarification of the functional properties of Fe-alginate 


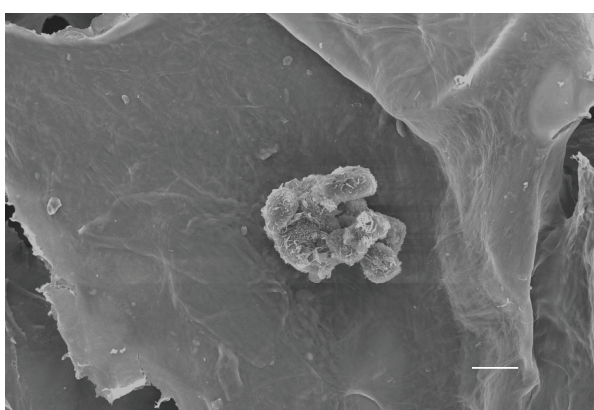

(a)

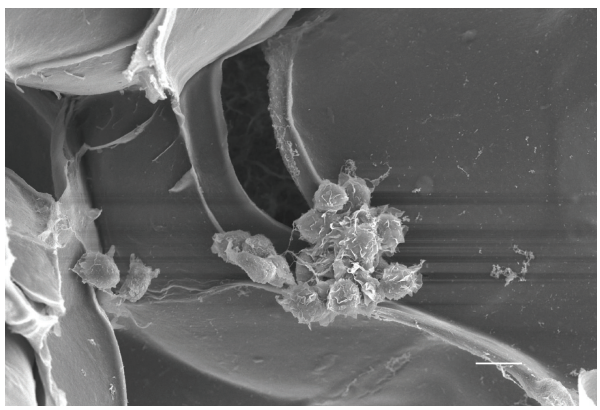

(c)

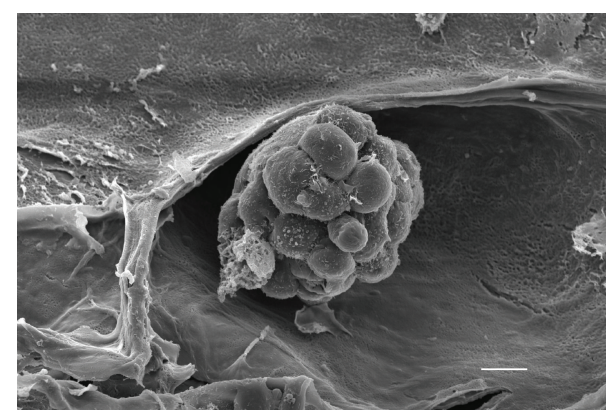

(b)

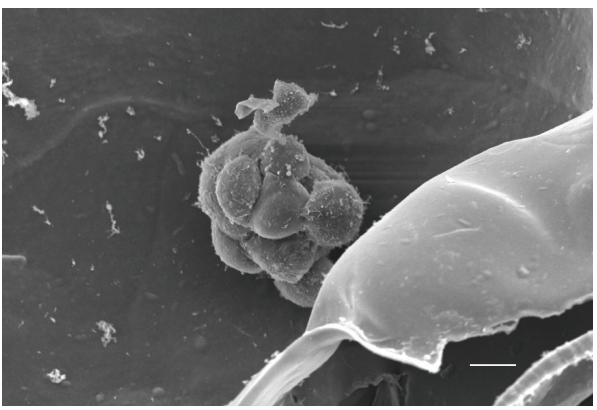

(d)

FIGURE 4: SEM micrographs of cells seeded onto Fe- ((a), (b)) and Ca- ((c), (d)) alginate scaffolds. Cells were cultured on each type of gels, and observed after 1 day ((a), (c)) and 14 days ((b), (d)) of culture. Bar equals $10 \mu \mathrm{m}$.

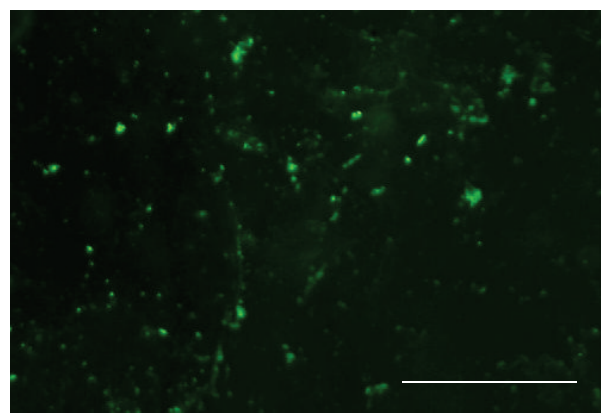

(a)

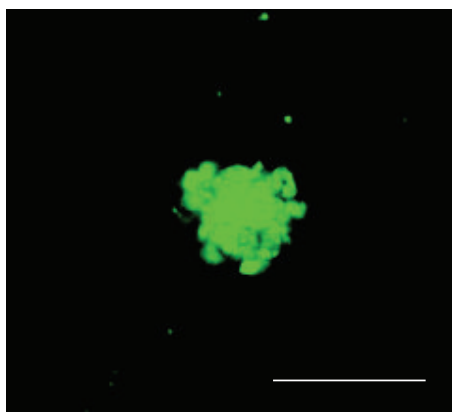

(b)

FigurE 5: Fluorescence micrographs of cells on Fe-alginate scaffolds. The viable cells were stained and observed after 14 days of culture. Bar equals $1000 \mu \mathrm{m}$ (a) or $100 \mu \mathrm{m}$ (b).

as a cell scaffold in various configurations might extend the range of its potential applications.

On the Fe-alginate scaffold, cells formed multicellular spheroids (Figures 4(a) and 4(b)). Cells forming spheroids are known to be able to maintain their specific functions exhibited in vivo $[1,4,5,12-16]$. It has been reported that cells such as hepatocytes or chondrocytes lose their function under monolayer culture conditions [1-3]. In the case of cancer cells, their behavior is similar to that in vivo when cultured as multicellular spheroids, unlike the situation under two-dimensional conditions [4, 5, 12-15]. These findings suggest that culture environments allowing cells to grow as spheroids would be very useful for many applications in a range of biomedical fields. Accordingly, the present study was performed to clarify the possibility of applying Fe-alginate for this purpose.

Many studies have reported methods for culture of cell spheroids focusing on the interactions between cells and culture substrates. Two types of surface properties of the culture substratum are known to affect the development of cell spheroids, one being unfavorable and the other partially favorable for cell adhesion. On surfaces unsuitable for cell adhesion, cells aggregate into spheroids because they show only minimal adhesion to the substratum surface [16-18]. However, under such conditions, cells are unable to show anchorage-dependent growth $[17,18]$. Therefore, when a nonadhesive culture substratum is used, the size of multicellular spheroids is dependent on the number of seeded cells [18]. 
In contrast, surfaces that allow partial or weak cell adhesion can also be used for multicellular spheroid cultivation. It has been reported that cells are able to proliferate when a proportion of the cells forming spheroids interact with the culture substrate [19]. Under such conditions, which allow cells to adhere to the material surface, small spheroids can grow into large ones [19]. It has been reported that integrin-mediated adhesion prompts cell growth [20] and that spheroid-forming ability is disturbed by inhibition of $\beta 1$ integrin function [21]. These findings suggest that integrinmediated interactions between cells and the scaffold play a critical role in the growth of multicellular spheroids.

In the present study, cell growth was observed only on Fe-alginate scaffolds (Figure 3), although cells formed multicellular spheroids on both $\mathrm{Fe}$ - and $\mathrm{Ca}$-alginate scaffolds (Figure 4). This suggested that cells seeded onto Fe-alginate interacted with the scaffold via integrin, unlike the situation on Ca-alginate. When cells attach to surfaces, they initially respond to the adsorbed extracellular proteins that are present there and adhere to them via integrin [22]. We found that $\mathrm{Fe}$-alginate exhibited higher protein adsorptive ability than Ca-alginate (Figure 2). In our previous study, we had observed a similar phenomenon in two-dimensional alginate gels, and the adsorption of protein onto the surface of Fealginate is considered to be a critical factor determining its suitability as a culture substrate for cells [7]. Ca-alginate is known to be highly hydrophilic, and such polymers are not very efficient in adsorbing protein [16]. Modification of Caalginate with cell-adhesion peptides (i.e., RGD) is required in order to allow it to act as a scaffold for cell growth [23]. A previous study has revealed that $\mathrm{Fe}$-alginate films have higher surface hydrophobicity than Ca-alginate films [7]. In threedimensional porous gels, as is the case for two-dimensional conditions, such differences in gel properties between $\mathrm{Fe}$ - and $\mathrm{Ca}$-alginate might alter their capacity for adsorbing proteins, thus determining their suitability as scaffolds. It is considered that Fe-alginate could support the formation of spheroids by providing both a protein-adsorbed surface and a threedimensional environment for cells.

Our observations of stained living cells revealed that they were distributed throughout the Fe-alginate gels and remained viable within multicellular spheroids even after cultivation for 14 days (Figure 5). Moreover, we succeeded in harvesting living multicellular spheroids cultured on a Fealginate scaffold by dissolving the scaffold with deferoxamine mesylate, a ferric ion-specific chelator (data not shown). Retrieving living spheroids is beneficial for biochemical analysis of cells after cultivation, and the harvested spheroids can be used as components for fabrication of tissue-like structures in the field of regenerative medicine. Therefore, Fealginate scaffolds are considered to be promising materials for cytological and tissue engineering.

\section{Conclusions}

In this study, we have evaluated for the first time the functions of three-dimensional porous Fe-alginate as a scaffold for cell culture. Fe-alginate gel was considered to be an effective material for three-dimensional cell cultivation, as it exhibited higher protein adsorptive ability and supported good cell growth, unlike Ca-alginate. Moreover, it was revealed that the cells on Fe-alginate scaffolds remained viable within multicellular spheroids even after cultivation for 14 days. These results suggest that three-dimensional porous Fe-alginate gels would be useful in various biomedical fields, including cellular research, drug development, and tissue engineering. Further investigations of the physiological functions of cells on Fe-alginate will be needed in order to better characterize the scaffold afforded by Fe-alginate gels.

\section{Conflict of Interests}

The authors declare that there is no conflict of interests regarding the publication of this paper.

\section{References}

[1] Y. Du, S.-M. Chia, R. Han, S. Chang, H. Tang, and H. Yu, "3D hepatocyte monolayer on hybrid RGD/galactose substratum," Biomaterials, vol. 27, no. 33, pp. 5669-5680, 2006.

[2] N. Fukui, Y. Ikeda, N. Tanaka et al., “ $\alpha \mathrm{V} \beta 5$ integrin promotes dedifferentiation of monolayer-cultured articular chondrocytes," Arthritis and Rheumatism, vol. 63, no. 7, pp. 19381949, 2011.

[3] K. von der Mark, V. Gauss, H. von der Mark, and P. Mueller, "Relationship between cell shape and type of collagen synthesised as chondrocytes lose their cartilage phenotype in culture," Nature, vol. 267, no. 5611, pp. 531-532, 1977.

[4] A. Birgersdotter, R. Sandberg, and I. Ernberg, "Gene expression perturbation in vitro: a growing case for three-dimensional (3D) culture systems," Seminars in Cancer Biology, vol. 15, no. 5, pp. 405-412, 2005.

[5] F. Hirschhaeuser, H. Menne, C. Dittfeld, J. West, W. MuellerKlieser, and L. A. Kunz-Schughart, "Multicellular tumor spheroids: an underestimated tool is catching up again," Journal of Biotechnology, vol. 148, no. 1, pp. 3-15, 2010.

[6] L. A. Kunz-Schughart, J. P. Freyer, F. Hofstaedter, and R. Ebner, "The use of 3-D cultures for high-throughput screening: the multicellular spheroid model," Journal of Biomolecular Screening, vol. 9, no. 4, pp. 273-285, 2004.

[7] I. Machida-Sano, Y. Matsuda, and H. Namiki, "In vitro adhesion of human dermal fibroblasts on iron cross-linked alginate films," Biomedical Materials, vol. 4, no. 2, Article ID 025008, 2009.

[8] O. Smidsrød and G. Skjåk-Bræk, "Alginate as immobilization matrix for cells," Trends in Biotechnology, vol. 8, no. 3, pp. 71-78, 1990.

[9] P. Sriamornsak and R. A. Kennedy, "Development of polysaccharide gel-coated pellets for oral administration. 2. Calcium alginate," European Journal of Pharmaceutical Sciences, vol. 29, no. 2, pp. 139-147, 2006.

[10] K. Smetana Jr., “Cell biology of hydrogels," Biomaterials, vol. 14, no. 14, pp. 1046-1050, 1993.

[11] J. A. Rowley, G. Madlambayan, and D. J. Mooney, "Alginate hydrogels as synthetic extracellular matrix materials," Biomaterials, vol. 20, no. 1, pp. 45-53, 1999.

[12] B. K. Jong, "Three-dimensional tissue culture models in cancer biology," Seminars in Cancer Biology, vol. 15, no. 5, pp. 365-377, 2005. 
[13] R. M. Sutherland, "Cell and environment interactions in tumor microregions: the multicell spheroid model," Science, vol. 239, no. 4849, pp. 177-184, 1988.

[14] J. L. Becker and D. K. Blanchard, "Characterization of primary breast carcinomas grown in three-dimensional cultures," Journal of Surgical Research, vol. 142, no. 2, pp. 256-262, 2007.

[15] H. Karlsson, M. Fryknäs, R. Larsson, and P. Nygren, "Loss of cancer drug activity in colon cancer HCT-116 cells during spheroid formation in a new 3-D spheroid cell culture system," Experimental Cell Research, vol. 318, no. 13, pp. 1577-1585, 2012.

[16] R. Glicklis, L. Shapiro, R. Agbaria, J. C. Merchuk, and S. Cohen, "Hepatocyte behavior within three-dimensional porous alginate scaffolds," Biotechnology and Bioengineering, vol. 67, no. 3, pp. 344-353, 2000.

[17] K. Steadman, W. D. Stein, T. Litman et al., "PolyHEMA spheroids are an inadequate model for the drug resistance of the intractable solid tumors," Cell Cycle, vol. 7, no. 6, pp. 818$829,2008$.

[18] Y.-S. Torisawa, A. Takagi, Y. Nashimoto, T. Yasukawa, H. Shiku, and T. Matsue, "A multicellular spheroid array to realize spheroid formation, culture, and viability assay on a chip," Biomaterials, vol. 28, no. 3, pp. 559-566, 2007.

[19] Y. Yoshii, A. Waki, K. Yoshida et al., "The use of nanoimprinted scaffolds as 3D culture models to facilitate spontaneous tumor cell migration and well-regulated spheroid formation," Biomaterials, vol. 32, no. 26, pp. 6052-6058, 2011.

[20] H. Mizushima, X. Wang, S. Miyamoto, and E. Mekada, "Integrin signal masks growth-promotion activity of HB-EGF in monolayer cell cultures," Journal of Cell Science, vol. 122, no. 23, pp. 4277-4286, 2009.

[21] Y. Yoshida, T. Kurokawa, Y. Nishikawa, M. Orisa, H. K. Kleinman, and F. Kotsuji, "Laminin-1-derived scrambled peptide AG73T disaggregates laminin-1-induced ovarian cancer cell spheroids and improves the efficacy of cisplatin," International Journal of Oncology, vol. 32, no. 3, pp. 673-681, 2008.

[22] C. J. Wilson, R. E. Clegg, D. I. Leavesley, and M. J. Pearcy, "Mediation of biomaterial-cell interactions by adsorbed proteins: a review," Tissue Engineering, vol. 11, no. 1-2, pp. 1-18, 2005.

[23] T. Re'em, O. Tsur-Gang, and S. Cohen, "The effect of immobilized RGD peptide in macroporous alginate scaffolds on TGF $\beta 1-$ induced chondrogenesis of human mesenchymal stem cells," Biomaterials, vol. 31, no. 26, pp. 6746-6755, 2010. 

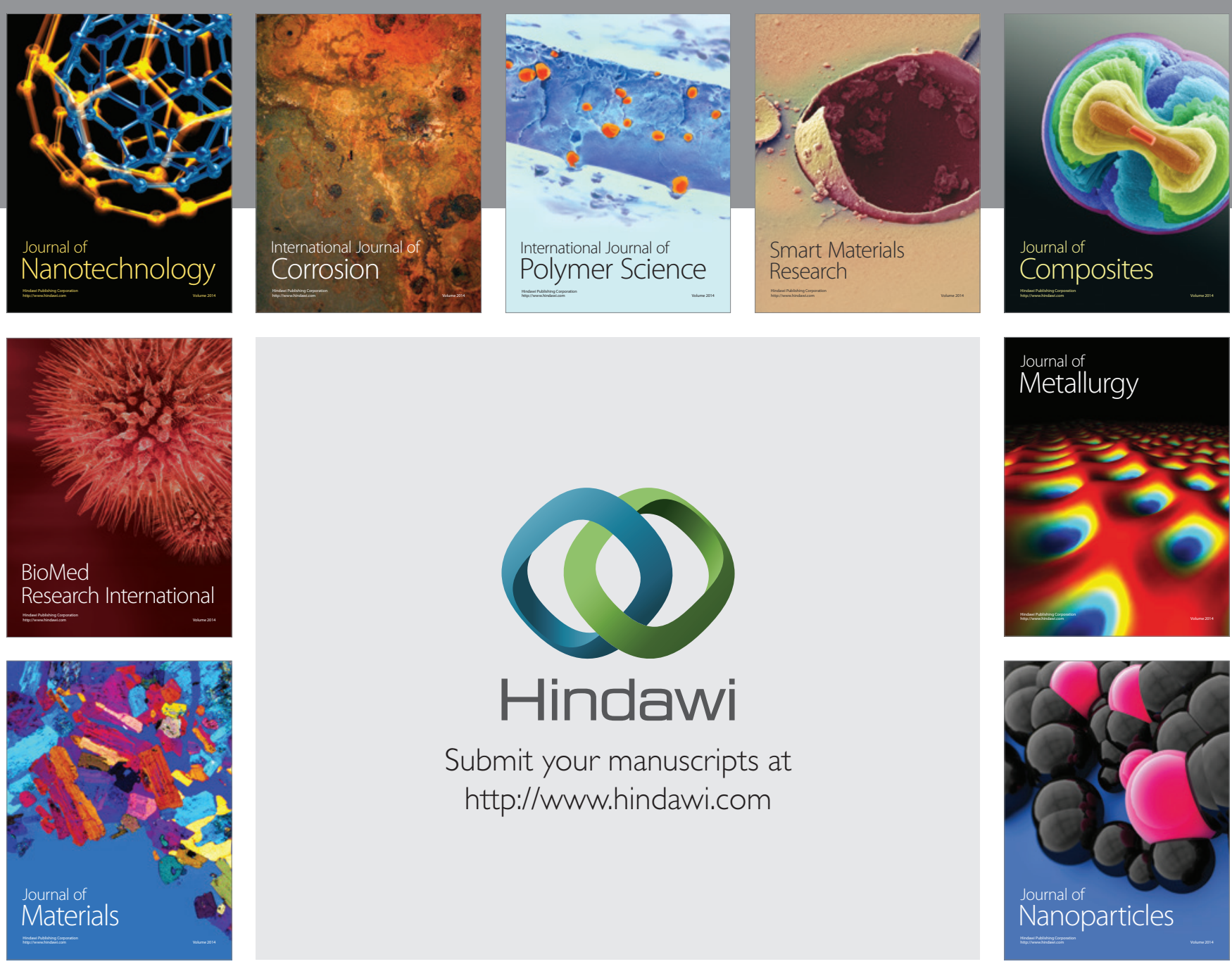

Submit your manuscripts at http://www.hindawi.com
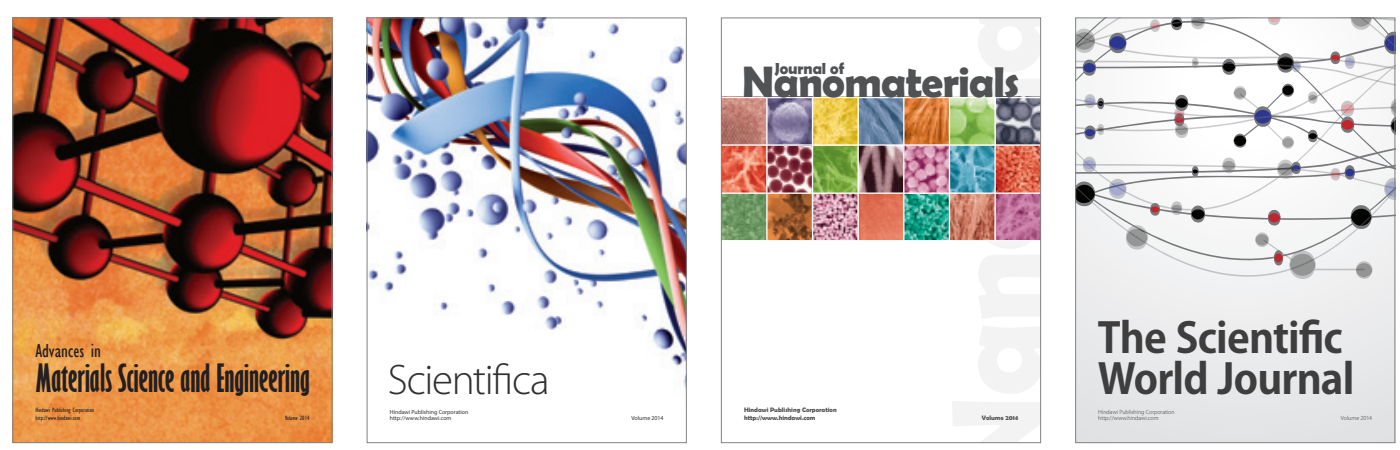

\section{The Scientific World Journal}
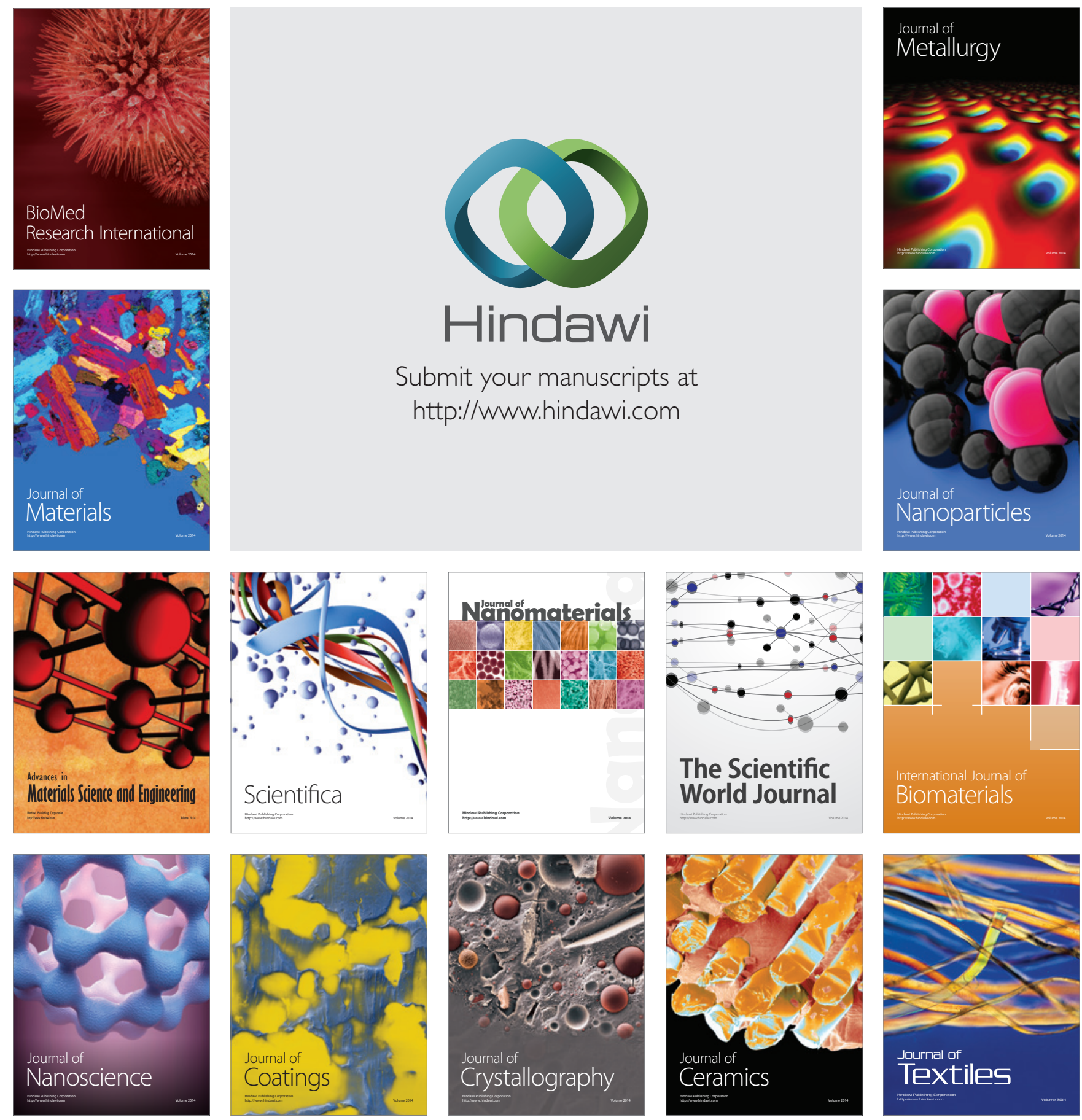